PONTIFÍCIA UNIVERSIDADE CATÓLICA DO RIO DE JANEIRO

Crescimento do Mercado de Bicicletas Elétricas para Locomoção Diária nas Grande Cidades O Que Favorece e o Que Limita Esse Crescimento?

Mateus Vieira Lendoiro

Trabalho de Conclusão de Curso

Centro de CiÊnCIAS SOCIAIS - CCS

Departamento de AdMinistração Graduação em Administração de Empresas 
Rio de Janeiro, Novembro de 2021. 
Mateus Vieira Lendoiro

\title{
Crescimento do Mercado de Bicicletas Elétricas para Locomoção Diária nas Grande Cidades \\ O Que Favorece e o Que Limita Esse Crescimento?
}

Trabalho de Conclusão de Curso

\begin{abstract}
Trabalho de Conclusão de Curso, apresentado ao programa de graduação em Administração da PUC-Rio como requisito parcial para a obtenção do titulo de graduação em Administração.
\end{abstract}

Orientador(a): João Renato de Souza Coelho Benazzi

Rio de Janeiro Novembro de 2021. 


\section{Agradecimentos}

Agradeço principalmente à toda minha família, pelo amor, carinho, apoio e incentivo incondicionais que me deram durante toda a minha vida.

Ao meu orientador, João Renato Benazzi, por todos os ensinamentos, conselhos, paciência e dedicação ao longo do curso.

À PUC-Rio e todos os professores que fizeram parte da minha trajetória neste curso, principalmente pela estrutura e qualidade de ensino oferecidas.

Aos meus amigos que estiveram junto comigo nessa longa jornada, pelo companheirismo, lealdade, confiança e espírito colaborativo.

A todos aqueles que, de alguma forma, contribuíram para a realização desse trabalho, seja direta ou indiretamente. 


\section{Resumo}

Lendoiro, Mateus Vieira. Benazzi, João Renato de Souza Coelho. Crescimento do Mercado de Bicicletas Elétricas para Locomoção Diária nas Grande Cidades: O Que Favorece e o Que Limita Esse Crescimento? Rio de Janeiro, 2021. 28 p. Trabalho de Conclusão de Curso Departamento de Administração. Pontifícia Universidade Católica do Rio de Janeiro.

O presente estudo buscou identificar os fatores que influenciam o crescimento do mercado de bicicletas elétricas, principalmente se tratando do seu uso para locomoção diária nas grandes cidades. Para isso, foi realizada uma pesquisa de campo, que contou com a participação de 5 usuários de bicicletas elétricas. A partir dos resultados obtidos, foi possível verificar os principais fatores que motivam a aquisição, além dos critérios utilizados por cada um deles no momento de decisão do modelo. Também foram abordadas questões sobre as características dos trajetos normalmente percorridos e as condições de uso da bicicleta, buscando compreender em que situações ela é usada e em que situações o seu uso é evitado. Por fim, foi perguntado sobre experiências negativas possivelmente vivenciadas e o nível de satisfação com a compra.

Palavras- chave

Bicicletas Elétricas. Mobilidade Urbana. Sustentabilidade.

\section{Abstract}

Lendoiro, Mateus Vieira. Benazzi, João Renato de Souza Coelho. Growth of Electric Bicycle Market for Daily Commuting in Big Cities: What Favors and What Limits This Growth? Rio de Janeiro, 2021. 28 p. Trabalho de Conclusão de Curso - Departamento de Administração. Pontifícia Universidade Católica do Rio de Janeiro.

The present study sought to identify the factors that influence the growth of the electric bicycle market, especially talking about its use for daily commuting in big cities. For this, a field research was carried out, with the participation of 5 electric bicycles users. From the results obtained, it was possible to verify the main factors that motivate the acquisition, in addition to the criteria used by each one of them when deciding on the model. The characteristics of the paths normally taken and the conditions for using the bicycle were also addressed, seeking to understand in which situations it is used and in which situations its use is avoided. Finally, they were asked about possibly negative experiences and the level of satisfaction with the purchase.

Key-words

Electric Bikes. Urban mobility. Sustainability. 


\section{Sumário}

1. Introdução 1

1.1. Contextualização 1

1.2. Problematização 3

1.3. Focalização 4

2. Referencial Teórico 5

2.1. Comportamento do Consumidor 5

2.1.1 Processo de Decisão de Compra do Consumidor 6

2.1.2 Estilo de Vida $\quad 7$

2.2. Sustentabilidade e Mobilidade Urbana 9

3. Métodos e procedimentos de coleta e análise de dados do estudo 13

3.1. Etapas de coleta de dados 13

3.2. Fontes de informação selecionadas para coleta de dados no estudo13

3.3. Procedimentos e instrumentos de coleta de dados utilizados no $\begin{array}{ll}\text { estudo } & 13\end{array}$

3.4. Formas de tratamento e análise dos dados coletados para o estudo 14

3.5. Limitações do Estudo

4. Apresentação e Análise dos Resultados 15

4.1. Os Entrevistados $\quad 15$

4.2. Descrição e Análise dos Resultados 15

4.2.1. Motivações Para a Aquisição $\quad 15$

4.2.2. Critérios de Escolha de Modelo 17

4.2.3. Características e Condições do Uso 19

4.2.3.1 O Percurso $\quad 21$

4.2.4. Satisfação dos Usuários 22

5 . Conclusões 24

5.1. Sugestões e Recomendações para Novos Estudos 25 


\section{Lista de figuras}

Figura 1: Pirâmide de Necessidades de Maslow ................................................. 6

Figura 2: Estilo de Consumo ................................................................. 9

Figura 3: Vendas/Emplacamentos de Veíuclos Elétricos no Brasil.............. 1Erro! Indicador não definido.

\section{Lista de Tabelas}

Nenhuma entrada de índice de ilustrações foi encontrada. 


\section{Introdução}

\subsection{Contextualização}

A degradação ambiental é um tema que vem se tornando mais pertinente de ser debatido ao decorrer dos anos, principalmente devido aos hábitos de consumo e práticas não sustentáveis que a população mundial adotou a partir das revoluções industriais.

A preocupação com a preservação ambiental não é um tema recente em nossa história. Os romanos já haviam colocado em prática algumas medidas para organizar o descarte de resíduos domiciliares. Aqui no Brasil, desde o período colonial, já existiam leis que tinham como objetivo a proteção dos recursos naturais, florestais e pesqueiros. Entretanto, a maioria dessa preocupação em preservar era fruto de interesses econômicos (Nascimento, 2012).

Em 1972, o meio ambiente foi discutido pela primeira vez pelos governos do mundo como um tema em si, problematizando a dependência existente entre desenvolvimento e meio ambiente. Isso aconteceu na Primeira Conferência sobre Meio Ambiente Humano, convocada pela ONU, em Estocolmo, na Suécia, reunindo 113 países, 19 órgãos intergovernamentais e mais de 400 organizações não governamentais (Sabbagh, 2011).

Com o passar dos anos, essa deterioração do meio ambiente foi somente ficando mais crítica, e atualmente esses temas de conscientização ambiental vem ganhando mais força e importância no contexto social, principalmente devido à facilidade na troca de informações existente. Podemos observar uma forte crescente na adoção de práticas mais conscientes, e a vinculação de imagens positivas a empresas que aderem esse tipo de atitude nas suas práticas produtivas.

Grande parte dessa degradação ambiental é causada pela emissão de gases poluentes na atmosfera, que agravam o efeito estufa a níveis extremamente prejudiciais à vida na Terra. Segundo Roberta Sabbagh (2011), a temperatura média do planeta pode subir em $4^{\circ} \mathrm{C}$.

O principal gás causador do efeito estufa é o dióxido de carbono (CO2), e é emitido principalmente pela queima de combustíveis fósseis (Sabbagh, 2011). 
Os motores à combustão, utilizados na grande maioria dos automóveis hoje em dia, são grandes vilões neste contexto, uma vez que utilizam esse tipo de combustível para gerar energia. Esses gases emitidos, além de prejudicar a natureza, também prejudicam os humanos, favorecendo o desenvolvimento de doenças respiratórias.

Além das questões ambientais, o uso dos carros em grande escala vem sendo responsável por gerar um trânsito caótico nas cidades, somando ao fato de possuírem altos custos de manutenção.

Atualmente, isso vem sendo repensado, e novos meios de transporte com fontes de energia alternativas vem surgindo, e o principal deles é o motor que trabalha com energia elétrica, atuando com emissão zero de poluentes.

Trazendo para o contexto Brasil, podemos observar que os carros elétricos ainda não são uma realidade, principalmente devido ao seu alto custo de aquisição e manutenção, e a carga tributária é a maior vilã dessa história. De acordo com Sugahara (2021), "O problema é que, em países da Europa, os veículos com mais eficiência energética pagam menos impostos e, no Brasil, acontece o oposto". Em nosso país, um motor à combustão que percorre entre 10 e 12 quilômetros por litro paga 7\% de IPI, enquanto um carro híbrido, que possui o auxílio de energia elétrica, e roda 25 quilômetros com um litro, chega a pagar até $15 \%$ de IPI (Sugahara, 2021). Para que se tornasse mais viável o alcance de um desenvolvimento mais sustentável, seria mais coerente se os veículos elétricos pagassem o mesmo IPI que um modelo 1.0 flex.

Apesar dessas barreiras, 0 mercado de bicicletas elétricas tem apresentado um forte crescimento nas grandes cidades de nosso país, e pode ser considerado uma ótima alternativa para alguns. De acordo com um estudo desenvolvido pela Associação Brasileira do Setor de Bicicletas (Aliança Bike) e o Laboratório de Mobilidade Sustentável (Labmob/UFRJ), esse mercado teve um crescimento médio de $34 \%$ ao ano entre 2016 e 2019, e a tendência de alta foi mantida para os próximos anos.

De acordo com Glaucia Pereira (2020), coordenadora executiva da Revista Bicicletas Elétricas, foi realizado um estudo por meio da coleta de dados primários e secundários, com mais de 400 usuários deste meio de transporte, e os resultados apontaram que $56 \%$ desses usuários, que utilizam a bicicleta elétrica para estudar ou trabalhar, antes costumavam se deslocar de automóvel.

Além das particulares, já conseguimos observar a chegada do modelo de bicicletas elétricas compartilhadas no Rio de Janeiro, tornando o seu acesso mais democrático. A startup Tembici e o Itaú Unibanco lançaram um projeto com 
essa finalidade, que é inédito na América Latina. De acordo com o site do UOL (2020), a expectativa da empresa é que essas novas bikes elétricas façam três vezes mais viagens do que as bicicletas tradicionais que já eram alugadas antes.

Entendendo essas questões, este estudo terá como principal objetivo entender por quais motivos o consumidor decide optar ou não pelo uso da bicicleta elétrica para a locomoção diária nas grandes cidades.

\subsection{Problematização}

As bicicletas e scooters elétricas disponíveis no mercado brasileiro hoje não representam uma boa solução para trajetos muito grandes e perigosos, como pistas de alta velocidade e longos trechos sem ciclovia. Esse fator acaba reduzindo bastante o seu escopo de atuação. Será que esse é o principal fator limitador, ou existem outros que são mais relevantes e decisivos?

De acordo com as normas do CONTRAN (2013), as bicicletas elétricas precisam atender às seguintes características:

a) potência nominal máxima de 350 watts;

b) velocidade máxima de $25 \mathrm{~km} / \mathrm{h}$ (quando a propulsão estiver apoiada pelo motor elétrico);

c) devem ser dotadas de sistema que garanta o funcionamento do motor somente quando o condutor pedalar;

d) não devem dispor de acelerador ou de qualquer outro dispositivo de variação manual de potência;

e) devem ser dotadas de indicador de velocidade, campainha, sinalização noturna dianteira, traseira e lateral, espelhos retrovisores em ambos os lados e pneus em condições mínimas de segurança;

f) uso obrigatório de capacete de ciclista.

Enquanto os carros elétricos ainda não representam uma solução viável em nosso país, é importante analisarmos até que ponto as bikes elétricas são capazes de suprir as mesmas necessidades desses consumidores, enquanto ainda respeitam as normas do CONTRAN.

Pelo fato de o mercado de bicicletas elétricas ainda ser relativamente novo, e estar em um período de constante crescimento, não conseguimos encontrar com facilidade muitos estudos sobre o seu comportamento e os respectivos fatores influenciadores. 
Dessa forma, entendemos que a pesquisa que será feita é relevante pois buscará ir além dos dados de crescimento deste mercado. Nesse estudo, buscaremos entender os principais fatores que motivam ou desmotivam o consumidor a escolher por esse meio de transporte no seu dia a dia, e entender até que ponto essas bicicletas elétricas são capazes de suprir as mesmas necessidades de carros e outros veículos que utilizam motores a combustão.

\subsection{Focalização}

A partir desse contexto, este estudo tem como objetivo entender o lado do consumidor, e analisar como essa substituição do veículo à combustão pela bicicleta elétrica ocorre.

Um forte candidato para ser considerado o fator limitador para o uso desse tipo de transporte pode ser a distância. Até que limite o consumidor considera válido realizar essa troca, se este for mesmo o fator decisivo?

Além disso, sabemos que os custos de aquisição de uma bicicleta elétrica não são baixos, o que também acaba limitando a grande maioria da classe trabalhadora brasileira de aderir a esse transporte, além do fato da distância da residência ao local de trabalho. Portanto, qual o perfil das pessoas que estão sendo mais adeptas a esse movimento?

Sabemos também, que ao fazer essa troca, o consumidor nem sempre está pensando nas questões ambientais. Os motivos podem ser os mais variados, uma vez que a bicicleta elétrica, além de ser ecologicamente sustentável, também proporciona diversos benefícios como: praticidade, agilidade, conforto, autonomia e até mesmo uma possível economia.

A adoção do uso diário de uma bike elétrica nos traz prós e contras, como tudo na vida. Quais são as facilidades e as dificuldades percebidas pelo público ao fazer essa troca? 


\section{Referencial Teórico}

\subsection{Comportamento do Consumidor}

De acordo com Solomon, "[...] o comportamento do consumidor é o estudo dos processos envolvidos quando indivíduos ou grupos selecionam, compram, usam ou descartam produtos, serviços, ideias, ou experiências para satisfazer necessidades e desejos." (SOLOMON, 2011, p.33).

Esse tipo de estudo busca compreender os motivos que levam o consumidor a decidir comprar um produto, e porque escolhe aquele em específico diante das outras opções disponíveis. Para isso, são estudados os pensamentos, sentimentos e atitudes dos consumidores. Esses aspectos podem resultar em mudanças de decisão por parte desses compradores, e por isso são importantes de serem pesquisados pelos profissionais da área de marketing.

Para a elaboração de um novo produto, assim como para idealização de sua estratégia de lançamento e criação de uma campanha de marketing adequada e eficiente, é imprescindível a abordagem deste tema. De acordo com Mattar (1999, p.158), "o objetivo de marketing ao pesquisar o comportamento, é entender melhor o consumidor e assim poder melhor antecipar ou prever o seu comportamento futuro".

Para poder entender melhor o comportamento do consumidor e as suas decisões de compra, o estudo que deve ser realizado recebe contribuições de diferentes áreas de conhecimento, como a psicologia, sociologia, antropologia social e economia (Rocha e Christensen, 1999).

Dentro deste tema, um ponto muito importante que deve ser estudado está relacionado às motivações que levam o consumidor a uma determinada decisão de compra. Não podemos entrar nesse assunto sem abordar a teoria da "Hierarquia das Necessidades", apresentada por Abraham Maslow.

Maslow defende que o indivíduo ordena as suas necessidades em uma hierarquia de prioridades, e apresenta essa ideia através de uma pirâmide. Na base dela estão representadas as necessidades mais básicas de um ser humano, relacionadas principalmente a questões de sobrevivência. Conforme os níveis da pirâmide vão subindo, a ordem de prioridade vai diminuindo, até que chegamos no topo da pirâmide, que é identificado como o nível de "Realização 
Pessoal", e deve ser o último a ser alcançado. O desenho da pirâmide é ilustrado conforme a imagem a seguir:

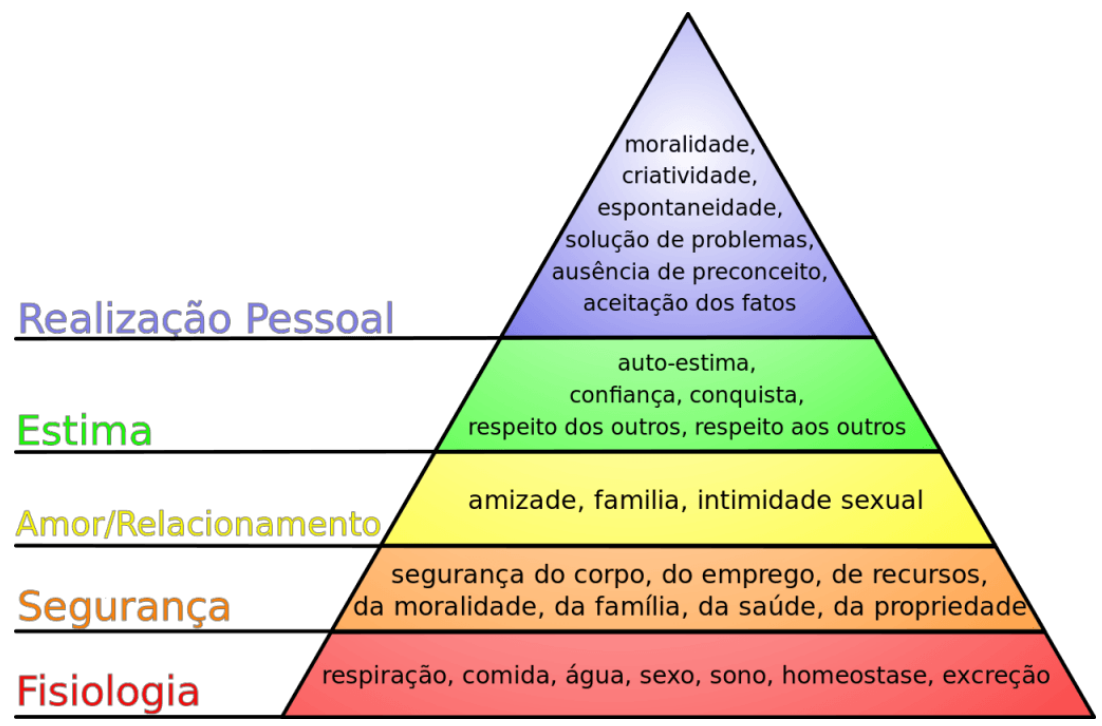

Figura 1: Pirâmide de Necessidades de Maslow. (Disponível em: https://endeavor.org.br/pessoas/piramide-de-maslow/. Acesso em: 21/06/2021)

Nos tempos atuais, observamos uma sociedade em constante mudança, portanto, tornam-se necessárias estratégias bem elaboradas para suprir as necessidades e desejos dos consumidores, visando alterações em curto espaço de tempo. Dessa forma, as empresas devem buscar sempre realizar inovações contínuas dos produtos, criando novas versões, novas marcas e novas estratégias (Peter e Olson, 2005).

\subsubsection{Processo de Decisão de Compra do Consumidor}

Para Engel, Blackwell e Miniard (2000), o processo de decisão de compra é composto por 6 etapas, sendo elas: 1- Reconhecimento da necessidade; 2Busca de informações; 3- Avaliação de alternativas pré-compra; 4- Compra; 5Avaliação pós-consumo; 6- Descarte. Para este trabalho, as etapas mais relevantes na tomada da decisão são as de "reconhecimento da necessidade" e "avaliação de alternativas pré-compra". Nelas, o consumidor poderá identificar se a bicicleta elétrica se encaixa ou não na sua rotina, e se trará benefícios para a locomoção diária se comparada às das outras opções de transporte disponíveis. Neste caso, os critérios para avaliação podem ser: custos mensais; conforto; praticidade; distância; aumento ou diminuição do tempo de percurso etc. 
Kotler e Keller (2012) apontam um modelo que defende que o comportamento de compra do consumidor é influenciado por 3 principais fatores, sendo eles: culturais, sociais e pessoais. Para eles, os fatores culturais são os que exercem a mais forte influência, uma vez que "a cultura é o principal determinante dos desejos e do comportamento de uma pessoa".

Trazendo esta reflexão para a questão da locomoção diária nas cidades, podemos perceber nitidamente que em alguns países a opção pelo uso de uma bicicleta como principal meio de transporte é expressivamente maior, e isso se dá justamente pela influência dos fatores culturais. Em alguns lugares, como acontece por exemplo na Alemanha e na Holanda, a bicicleta é vista como um meio de transporte extremamente prático e sustentável, e isso a coloca em uma posição de muito mais respeito e atenção, se comparada a outros países, como o próprio Brasil.

Especificamente no contexto abordado, também podemos compreender o fator social como um grande limitador para a adoção do uso de bicicletas elétricas no dia a dia, visto que no Brasil possuímos uma malha cicloviária muito restrita, que acaba viabilizando o uso seguro e adequado da bike somente para uma parcela bem limitada da população, que mora em determinadas regiões.

\subsubsection{Estilo de Vida}

Outro fator que também exerce importante influência nas decisões de compra de um consumidor é o seu estilo de vida. Giddens (2002) define estilo de vida como "um conjunto mais ou menos integrado de práticas que um indivíduo abraça, não só porque essas práticas preenchem necessidades utilitárias, mas porque dão forma material a uma narrativa particular de autoidentidade." O mesmo autor ainda diz que: "os estilos de vida são práticas rotinizadas, as rotinas incorporadas em hábitos de vestir, comer, modos de agir e lugares preferidos de encontrar os outros; mas as rotinas seguidas estão reflexivamente abertas à mudança à luz da natureza móvel da autoidentidade."

Para Solomon (2015), "O estilo de vida define o padrão de consumo que reflete as escolhas de uma pessoa sobre como despender seu tempo e dinheiro". Sabendo disso, é extremamente agregador para os profissionais de marketing a realização de uma pesquisa baseada no estilo de vida, pois dessa forma se torna possível posicionar produtos e serviços com mais precisão, realizando a segmentação correta. 
Nas sociedades mais tradicionais, o consumo é diretamente influenciado pela classe, casta, aldeia ou família. Entretanto, na sociedade de consumo moderna, pelo fato de as pessoas serem mais livres, uma maneira comum de afirmar sua personalidade e identidade é a partir do processo de escolha sobre quais produtos ou serviços irão consumir. Dessa forma, as pessoas buscam afirmar quem são e quem não são na sociedade.

Apesar dessa maior liberdade na sociedade moderna, ainda existem alguns fatores que são responsáveis por influenciar o estilo de vida de um indivíduo, como por exemplo a quantidade de dinheiro e de tempo que ele tem disponível. Com pouco recurso financeiro a disposição, o consumidor lida com maiores limitações e restrições na hora de selecionar os produtos e serviços que irá consumir, muitas vezes tendo que deixar os gostos de lado e optar pelo mais barato. Já os que possuem pouco tempo disponível, provavelmente irão dar prioridades para o que é mais prático, rápido e conveniente. No caso da bicicleta elétrica, percebemos que é um produto mais viável para pessoas que possuem uma condição financeira mais confortável, e dependendo do trajeto a ser percorrido no dia a dia, pode trazer a eficiência desejada para o transporte do consumidor que possui uma rotina mais corrida e busca fugir do engarrafamento da cidade.

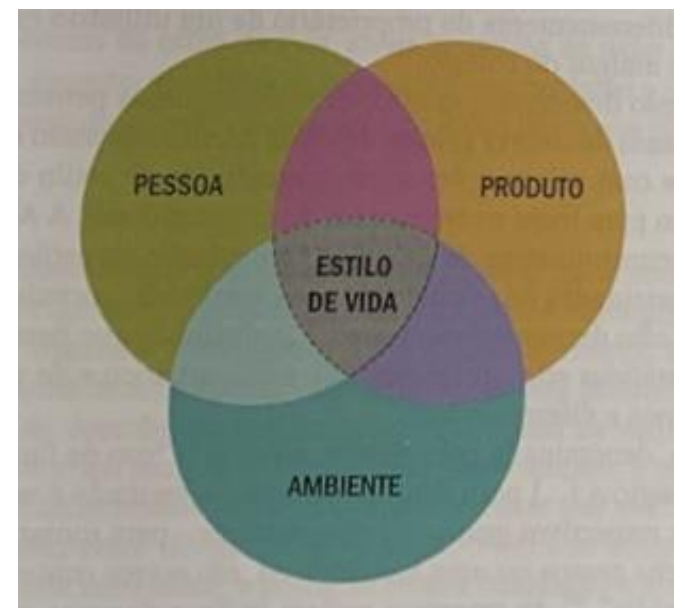

Figura 2: Estilo de consumo

Fonte: O comportamento do consumidor: comprando, possuindo e sendo; p. 487; Solomon (2015)

Um dos principais objetivos do marketing de estilo de vida é proporcionar aos consumidores a possibilidade de aproveitar a vida da forma que mais o agradar, e ao mesmo tempo expressar a sua identidade social utilizando os 
produtos em ambientes sociais desejáveis. Dessa forma, há uma associação entre pessoas, produtos e ambiente, com a finalidade de expressar um estilo de consumo, como é representado na figura 2 (Solomon, 2015).

A partir da identificação de costumes, preferências e valores pessoais, criam-se subculturas de estilo de vida, e cada uma delas possui seu conjunto próprio e único de normas, vocabulário e insígnias de produto. Solomon (2015) cita como um exemplo a subcultura tuner, que é formada por "homens solteiros já no final da adolescência e início dos 20 , normalmente em comunidades latinas ou asiáticas, que têm em comum uma paixão por carros velozes, aprimoramentos automotivos de alta tecnologia e peças de carro especializadas." Essas subculturas, normalmente, se formam com base em alguns personagens de ficção e eventos, e colaboram para a definição do eu estendido.

Muitos produtos e serviços podem ser considerados complementares, uma vez que parecem "andar de mãos dadas" e normalmente são consumidos pelo mesmo tipo de pessoa nas mesmas situações. Portanto, Solomon (2015) aponta que um elemento fundamental para o marketing de estilo de vida é a capacidade de identificação do conjunto de produtos e serviços que os consumidores associam a determinado estilo de vida. Uma estratégia muito utilizada para explorar esse elemento do marketing é a de associação de marcas, ou "cobranding", na qual empresas percebem uma relação entre categorias e se juntam umas às outras com a finalidade de promover dois ou mais de seus produtos.

Portanto, diante das definições apresentadas e contextualizando com o produto abordado neste trabalho, presume-se que pessoas que possuem um estilo de vida mais ativo e saudável, que se preocupam com o meio ambiente e também buscam autonomia e independência, são mais propícias a adotarem o uso habitual de uma bicicleta elétrica que os demais.

\subsection{Sustentabilidade e Mobilidade Urbana}

A mobilidade é um recurso social extremamente relevante no dia a dia da população, uma vez está diretamente ligado à capacidade de deslocamento entre diferentes espaços geográficos, que é fundamental na rotina de quase todos, principalmente os que habitam áreas urbanas.

Podemos identificar diversos fatores que interferem diretamente na mobilidade de cada indivíduo, como por exemplo: idade, gênero, renda, trabalho, 
localização geográfica entre outros. De acordo com Kleiman (2011), esses fatores são responsáveis por diferenciar e determinar condições individuais e coletivas quando tratamos de mobilidade no espaço urbano.

O EUROFORUM (2007) defende que o suporte à mobilidade é essencial para que as cidades possam cumprir o seu papel social e, juntamente com isso, viabilizar o crescimento econômico. Entretanto, não podem desconsiderar os impactos negativos do tráfego motorizado, e devem tentar sempre limitá-lo, buscando controlar e diminuir os impactos negativos sobre as pessoas e o meio ambiente. $\mathrm{O}$ uso de meios de transporte que não realizam a combustão, como é o caso das bicicletas elétricas, se apresenta como um forte candidato e uma potencial solução para a redução dos danos causados pela emissão dos gases na atmosfera.

Portanto, precisamos ter em mente que é fundamental a preocupação com um desenvolvimento sustentável, que é definido pelo PLUME (2003) como: "uma forma de desenvolvimento que vai de encontro às necessidades da geração atual sem comprometer a possibilidade (ou capacidade) das gerações futuras em satisfazer as suas necessidades"

A European Enviromental Agency- EEA (1995) destaca 5 princípios urbanos de sustentabilidade, destacados abaixo:

1. Capacidade Ambiental: os limites naturais da cidade devem ser respeitados nas projeções e gerenciamentos.

2. Reversibilidade: o planejamento das intervenções nas cidades deve ser reversível, de maneira a não comprometer a capacidade de adaptação a novas demandas por mudanças nas atividades econômicas e da população sem atrapalhar a capacidade ambiental.

3. Resistência: a cidade deve ser capaz de se recuperar de pressões externas.

4. Eficiência: conseguir o maior retorno econômico possível para cada recurso natural utilizado e o maior benefício humano em cada atividade econômica.

5. Igualdade: democratizar o acesso às atividades e serviços para todos os habitantes.

Com base nesses princípios, a EEA (1995) também definiu algumas metas para que uma cidade possa se tornar sustentável, sendo elas:

- Minimização do consumo de espaço e de recursos naturais;

- Racionalização e gerenciamento eficientes dos fluxos urbanos;

- Proteção à saúde da população urbana; 
- Afirmação de acesso igualitário a recursos e serviços;

- Preservação da diversidade social e cultural.

A partir dessas questões apresentadas, que vinculam a sustentabilidade à mobilidade urbana, podemos perceber que as bicicletas elétricas são produtos que possuem um forte apelo ecológico como diferencial, uma vez que funcionam com emissão zero de gases, e por isso deveriam receber prioridades se comparadas a outros meios de transporte.

A bicicleta elétrica é, sem dúvidas, um produto que se beneficia do marketing verde, uma vez que é ambientalmente responsável por si própria. De acordo com Langer (2008, p1) "O marketing verde se refere ao processo de venda de produtos e serviços baseado nos seus benefícios ambientais." Para ele, "a presunção óbvia é a de que existe um grupo crescente de consumidores conscientes, preocupados com a sustentabilidade do planeta, e que tomarão a decisão de compra com base no benefício ambiental".

Apesar de parecer um assunto extremamente novo, os veículos elétricos não são uma inovação tão recente assim, e já eram populares no início do século XX. Entretanto, devido ao avanço da tecnologia do petróleo e seu baixo custo, os veículos à combustão superaram a popularidade e acabaram se desenvolvendo mais que os elétricos (Castro, 2010).

Os veículos que funcionam à base de gasolina e álcool foram e ainda são dominantes no mercado há aproximadamente um século, e isso ocorre pois eles conseguem ser melhores que os elétricos em três pontos muito importantes: autonomia, tempo de abastecimento e custo do veículo (incluindo preço da bateria e importação). Apesar da inferioridade nesses fatores, o motor movido à energia elétrica consegue ser até quatro vezes mais eficiente que o de combustão interna (Santamarta 2009).

De acordo com Velloso (2010), o custo de manutenção dos veículos elétricos é inferior ao dos veículos à combustão, uma vez que sua composição de peças é de menor complexidade. O motor de um automóvel elétrico possui apenas três peças, além de não contar com caixa de marchas e nem óleo lubrificante, enquanto o veículo movido à combustão possui de 300 a 400 peças.

De acordo com a ABVE (2021), as vendas de veículos elétricos no Brasil bateram um novo recorde no ano de 2020, e o aumento no número de emplacamentos em relação ao ano de 2019 foi de 66,5\%. Além disso, pela primeira vez na história, o mercado de eletrificados chegou a representar $1 \%$ do total de veículos do país. Na figura abaixo está ilustrada uma tabela que 
representa os números das vendas de veículos elétricos no Brasil, do ano de 2012 até 2020.

\begin{tabular}{|c|c|c|c|c|c|c|c|c|c|c|c|c|c|}
\hline \multicolumn{14}{|c|}{$\begin{array}{r}\text { Vendas/emplacamentos de veículos elétri } \\
\qquad 2012 \text { a dezembro } 2020\end{array}$} \\
\hline & Jan & Fev & Mar & $\mathrm{Abr}$ & Mai & Jun & Jul & Ago & Set & Out & $\mathrm{Nov}$ & Dez & Total Ano \\
\hline 2012 & 9 & 16 & 7 & 3 & 13 & 23 & 5 & 3 & 2 & 2 & 18 & 16 & 117 \\
\hline 2013 & 45 & 22 & 53 & 50 & 12 & 29 & 65 & 45 & 23 & 39 & 52 & 56 & 491 \\
\hline 2014 & 93 & 61 & 65 & 53 & 94 & 52 & 61 & 79 & 71 & 53 & 87 & 86 & 855 \\
\hline 2015 & 72 & 56 & 61 & 73 & 72 & 74 & 74 & 100 & 82 & 55 & 65 & 62 & 846 \\
\hline 2016 & 58 & 64 & 60 & 137 & 41 & 91 & 48 & 59 & 79 & 93 & 159 & 202 & 1091 \\
\hline 2017 & 178 & 157 & 227 & 176 & 208 & 238 & 268 & 627 & 384 & 243 & 240 & 350 & 3296 \\
\hline 2018 & 272 & 254 & 367 & 367 & 302 & 382 & 262 & 262 & 286 & 405 & 374 & 437 & 3970 \\
\hline 2019 & 370 & 287 & 336 & 290 & 357 & 716 & 960 & 867 & 1264 & 1989 & 2013 & 2409 & 11858 \\
\hline 2020 & 1568 & 2053 & 1570 & 442 & 601 & 1334 & 1668 & 1943 & 2113 & 2273 & 2231 & 1949 & 19745 \\
\hline TOTAL & & & & & & & & & & & & & 42269 \\
\hline
\end{tabular}

VEs=veículos híbridos não plug-in (HEV) + veículos hibridos plug-in (PHEV) + veículos elétricos $100 \%$ a bateria (BEV). Automóveis e comerciais leves. Exclui ônibus, caminhões, motos e levíssimos.

Figura 3: Vendas/emplacamentos de veículos elétricos no Brasil (Disponível em: http://www.abve.org.br/2020-o-melhor-ano-da-eletromobilidadeno-brasil/)

Apesar de ser uma tendência e o mercado apresentar crescimento, os carros elétricos ainda não são viáveis para a grande maioria da população brasileira e possuem uma representatividade baixa no cenário de mobilidade atual. Assim, podemos observar as bicicletas como responsáveis por possuírem um forte potencial para desempenhar um papel importante nesse ramo de veículos movidos a energia elétrica atualmente. 


\section{Métodos e procedimentos de coleta e análise de dados do estudo}

\subsection{Etapas de coleta de dados}

Os dados foram coletados a partir da abordagem qualitativa, que de acordo com Roberto Pinheiro (2004), é indicada quando se busca explorar o objeto de estudo de uma maneira mais profunda.

A pesquisa contou com apenas uma etapa de coleta de dados no campo, que foi a realização de entrevistas com 5 diferentes usuários de bicicletas elétricas.

\subsection{Fontes de informação selecionadas para coleta de dados no estudo}

Como fonte de respostas para as perguntas propostas pela pesquisa qualitativa, foram selecionados 5 usuários de bicicletas elétricas, que expuseram seus pontos através das entrevistas.

A seleção desses entrevistados se deu por conveniência e acessibilidade, visto que todos eram amigos ou pessoas indicadas por amigos.

Quanto ao perfil dos entrevistados, foram procurados jovens que utilizassem suas bicicletas elétricas com certa frequência, que fossem moradores do Rio de Janeiro e que possuíssem condições de vida minimamente semelhantes.

\subsection{Procedimentos e instrumentos de coleta de dados utilizados no estudo}

Para realizar a investigação, a coleta de dados foi feita a partir da realização de entrevistas, que ocorreram de maneira 100\% online, através da ferramenta Zoom, visto que a pesquisa aconteceu durante a pandemia do Covid19 na qual estamos buscando evitar o máximo possível de contato físico. 
O objetivo das entrevistas foi de entender os motivos que levam o indivíduo a optar ou não pelo uso de uma bicicleta elétrica como meio de transporte, buscando entender também 0 perfil, as preferências e 0 comportamento desse tipo de consumidor.

As perguntas realizadas abordavam temas como a motivação principal da compra, critérios para escolha do modelo, há quanto tempo possui a bicicleta, se há disponibilidade de ciclovia nos trajetos, frequência de uso, distância média percorrida por saída, e se já passou por alguma dificuldade que gerou arrependimento da escolha.

\subsection{Formas de tratamento e análise dos dados coletados para 0 estudo}

As entrevistas foram gravadas, de maneira que pudessem ser escutadas novamente após o momento da realização, com o intuito de facilitar o registro de maneira escrita dos dados e possibilitar uma análise mais adequada. Foi realizada análise de conteúdo das falas dos entrevistados como tratamento dos dados coletados.

As respostas obtidas foram comparadas entre si, com o objetivo de investigar a existência de algum padrão nos comportamentos e perceber as semelhanças entre os usuários.

\subsection{Limitações do Estudo}

Uma grande limitação do estudo realizado se encontra na fonte de obtenção dos dados, mais especificamente no seu volume. Levando em conta a quantidade de usuários de bicicleta elétrica existente, o número de pessoas entrevistadas não é o suficiente para afirmar que os dados coletados refletem o comportamento de todo esse público.

Além disso, como os entrevistados foram selecionados por acessibilidade, pode ser que a variação dos tipos de perfil não seja tão grande, tornando o método menos adequado para a realização de uma análise mais ampla e abrangente. 


\section{Apresentação e Análise dos Resultados}

\subsection{Os Entrevistados}

A pesquisa contou com entrevistas realizadas com 5 diferentes usuários de bicicletas elétricas, cujos dados estão representados na tabela 1 , que se encontra abaixo.

Tabela 1: Informações dos Entrevistados

\begin{tabular}{|c|c|c|c|}
\hline \multicolumn{4}{|c|}{ Dados dos Entrevistados } \\
\hline Nome & Gênero & Idade & Bairro \\
\hline Beatriz Fuchshuber & Feminino & 24 & Copacabana \\
\hline Gustavo Schaimberg & Masculino & 22 & Leblon \\
\hline João Pedro Tude & Masculino & 22 & Recreio \\
\hline Maria Eduarda Parada & Feminino & 19 & Copacabana \\
\hline Victor Paiva & Masculino & 23 & Lagoa \\
\hline
\end{tabular}

Fonte: Próprio Autor (2021)

Podemos observar que a faixa etária dos entrevistados é muito próxima, e varia entre os 19 e 24 anos. Além disso, 4 dos 5 entrevistados são moradores da Zona Sul do Rio de Janeiro, enquanto o último mora na Zona Oeste.

Como visto no referencial teórico, Kleiman (2011) faz menção à alguns fatores que são responsáveis por determinar as condições individuais e coletivas quando falamos de mobilidade no espaço urbano. Dentre esses fatores, estão a idade e a localização geográfica, que, como podemos perceber na tabela 1, não por acaso são muito semelhantes entre os entrevistados.

\subsection{Descrição e Análise dos Resultados}

\subsubsection{Motivações Para a Aquisição}

Durante a entrevista, foi perguntado para os participantes se eles utilizavam a bicicleta convencional antes de adquirir a elétrica, com a finalidade de avaliar a possível correlação entre as duas e a influência gerada na compra. Os resultados estão expressos na tabela 2 abaixo, acompanhados do respectivo tipo de uso.

Tabela 2: Uso da Bicicleta Convencional 


\begin{tabular}{|l|c|c|}
\hline \multicolumn{1}{|c|}{ Entrevistado } & $\begin{array}{c}\text { Andava de bicicleta comum antes } \\
\text { de adquirir a elétrica? }\end{array}$ & Como era o uso? \\
\hline Beatriz Fuchshuber & Sim & Apenas lazer \\
\hline Gustavo Schaimberg & Sim & Lazer e transporte \\
\hline João Pedro Tude & Sim & Lazer e transporte \\
\hline Maria Eduarda Parada & Não & - \\
\hline Victor Paiva & Sim & Lazer e transporte \\
\hline
\end{tabular}

Fonte: Próprio Autor (2021)

Analisando as respostas, percebemos que 4 dos 5 entrevistados já andavam de bicicleta antes, mas apenas 3 deles utilizavam como meio de transporte. Para esses que já usavam com essa finalidade, foi relatado que a frequência de uso aumentou, assim como a distância tolerada para o trajeto. Nesse caso, a bicicleta elétrica foi vista como um "upgrade" em relação à convencional, com o intuito de diminuir o tempo de percurso, trazer uma maior comodidade e evitar a transpiração gerada pelo esforço, fazendo com que ela possa ser usada em mais ocasiões.

Gustavo comprou sua bicicleta juntamente com o seu ingresso na faculdade, com o intuito de realizar a locomoção diária até o local de estudo, pois morava no Leblon e precisaria ir até a Gávea. Para ele, esse seria o método mais ágil, inteligente e agradável de realizar esse trajeto.

Além do "upgrade" em relação a sua bicicleta antiga, João Pedro informou que a compra foi realizada visando não só a sua própria locomoção, mas também a de toda sua família, visto que em sua casa apenas 2 de 4 pessoas possuem $\mathrm{CNH}$, e esse seria o melhor método para garanti-las a autonomia desejada.

Percebemos então que, por contar com o auxílio de um motor, o uso da bicicleta elétrica é muito mais voltado para a finalidade de transporte. O que vemos na bicicleta comum é um uso mais diversificado, podendo ser tanto para a locomoção entre curtas distâncias, como para fins de lazer e prática de atividade física, caracterizando um uso mais casual e menos frequente que a versão elétrica.

Também relacionado ao tópico de motivações para a aquisição, foi perguntado para os entrevistados se a questão ambiental teve um peso que influenciou na escolha. Todos os entrevistados afirmaram que a compra foi principalmente motivada pela questão da praticidade e da economia, e que a questão da sustentabilidade não foi tão relevante para a decisão. Entretanto, foi relatado que essa característica é, sem dúvidas, muito importante e agrega mais valor ao produto, visto que na maioria das vezes que ele é utilizado a pessoa 
está deixando de se locomover por outro meio de transporte que seria mais poluente e traria maiores impactos negativos para o futuro da natureza.

Esses impactos positivos no meio ambiente, causados pela adesão ao uso de bicicletas elétricas, vão diretamente de encontro com os conceitos de desenvolvimento sustentável no cenário mobilidade urbana, dados pelo PLUME (2003), citados no referencial teórico desse trabalho.

\subsubsection{Critérios de Escolha de Modelo}

Durante a entrevista também foi perguntado sobre os critérios levados em consideração no momento de decidir o modelo de bicicleta a ser comprado, visto que temos das mais variadas opções disponíveis no mercado. A tabela 3 nos mostra os principais fatores que influenciaram essa decisão, de acordo com cada um dos entrevistados.

Tabela 3: Fatores Influenciadores

\begin{tabular}{|c|c|}
\hline Entrevistado & Fatores levados em conta na hora da escolha do modelo \\
\hline Beatriz Fuchshuber & Preço; Tamanho \\
\hline Gustavo Schaimberg & Preço e relação custo/benefício \\
\hline João Pedro Tude & Potência \\
\hline Maria Eduarda Parada & Potência \\
\hline Victor Paiva & Preço \\
\hline
\end{tabular}

Fonte: Próprio Autor (2021)

No primeiro momento, percebemos que o preço era uma condição importante para 3 dos 5 entrevistados, enquanto os outros 2 eram menos sensíveis à isso.

Victor comentou que as bicicletas que estavam disponíveis para compra quando adquiriu a sua não eram de tão boa qualidade, e os seus preços eram altos. Com base nisso, percebeu que para ele seria mais vantajoso importar os componentes necessários e adaptar a sua própria bicicleta convencional para que se tornasse elétrica, e foi o que fez. Apesar de ter sido necessário levar à uma oficina para concluir a montagem, e o processo envolver mais esforços do que simplesmente comprar uma bike pronta, ficou feliz com o resultado e conseguiu economizar o dinheiro.

Gustavo também foi sensível ao preço, porém de uma maneira diferente: ao comparar diferentes modelos, percebeu que a marca Blitz apresentava uma relação custo/benefício melhor que a marca mais popular, a Lev. Com isso, verificou que com o mesmo valor da bicicleta mais básica disponível na Lev, que possuía bateria de chumbo, ele conseguiria comprar um modelo da Blitz que 
oferecia a bateria de Lítio. Levando em conta que essa bateria possui uma tecnologia melhor e normalmente é mais cara, ele tomou a decisão de comprar a bicicleta da Blitz por avaliar como a melhor relação custo/benefício.

Beatriz também levou em consideração o preço na hora de fazer a sua escolha, pois não estava disposta a desembolsar uma grande quantidade de dinheiro e buscava um modelo mais básico, sem necessidade de muitos diferenciais. Entretanto, esse não foi o único fator que influenciou a sua escolha, visto que também tinham outros 2 pontos importantes para se pensar. Ela disse morar em um prédio no qual há a necessidade de colocar a sua bike dentro do elevador, então buscou um modelo mais leve e compacto, que facilitaria essa situação. Sabemos que existem modelos dobráveis, porém estavam acima do preço que Beatriz gostaria de pagar, e esse de aro e quadro menores já era o suficiente para resolver seus problemas. Por último, ela também comentou que tem uma filha de 2 anos e, por isso, buscava um modelo que fosse resistente e compatível com a instalação da cadeirinha para crianças, concluindo então a sua decisão de compra.

Já para João Pedro e Maria Eduarda, o preço foi o fator que teve menos peso na escolha. Ambos relataram preferir pagar mais caro para possuir uma bicicleta mais potente, com maior força de arrancada e velocidade final, otimizando ainda mais a locomoção. João disse que alguns trechos do seu percurso são perigosos, pois necessita andar na rua junto aos carros, e isso teve grande peso para que decidisse por um modelo mais potente, já que dessa forma conseguiria sair de algumas situações difíceis com mais agilidade.

É importante dizer também que Maria Eduarda já possuiu outros diferentes modelos de bicicleta elétrica antes do atual, visto que já utiliza esse meio de transporte há 7 anos. Seus critérios de escolha já foram outros no passado, entretanto, diante de toda a experiência adquirida ao longo desse tempo de uso, hoje em dia prefere investir mais dinheiro para obter um produto melhor.

Diante dessas variadas questões envolvidas no processo de escolha do modelo de bicicleta elétrica, percebemos as necessidades abordadas por Peter e Oslon (2005) no que se diz a inovações. Como visto no referencial teórico, a sociedade moderna está em constante mudança, e a partir disso também vão se alterando as necessidades e desejos dos consumidores. Para atender essa variação de critérios avaliados no momento da compra, torna-se necessária, por parte das empresas, a criação de novas versões e estratégias para seus produtos. 


\subsubsection{Características e Condições do Uso}

Nesta parte da pesquisa foi procurado entender de maneira mais profunda como é o uso da bicicleta elétrica por cada um dos entrevistados, e diferentes questões foram abordadas para realizar essa análise.

$\mathrm{Na}$ tabela 4, que se encontra abaixo, são informados o tempo de experiência com a bicicleta e respectiva frequência de uso.

Tabela 4: Experiência Com o Uso

\begin{tabular}{|l|c|c|}
\hline \multicolumn{1}{|c|}{ Entrevistado } & Há quanto tempo possui a bike? & $\begin{array}{l}\text { Qual a frequência média } \\
\text { de uso? }\end{array}$ \\
\hline Beatriz Fuchshuber & 7 meses & Todos os dias \\
\hline Gustavo Schaimberg & 4 anos & Todos os dias \\
\hline João Pedro Tude & 1 ano e 6 meses & 3 a 4 vezes na semana \\
\hline Maria Eduarda Parada & $\begin{array}{c}7 \text { anos desde a primeira, 8 meses } \\
\text { com a atual }\end{array}$ & Todos os dias \\
\hline Victor Paiva & 8 anos & 3 a 4 vezes na semana \\
\hline
\end{tabular}

Fonte: Próprio Autor (2021)

Vemos então que o tempo de experiência com o uso da bicicleta elétrica é altamente variável quando comparamos as respostas fornecidas pelos usuários. Enquanto um deles possui sua bicicleta há apenas 7 meses, outro já é usuário há 8 anos.

Conseguimos perceber também que o uso da bicicleta elétrica é bastante frequente para todos os entrevistados, sendo que 3 deles relataram usar todos os dias da semana. Como visto no referencial teórico, para Giddens (2002), "os estilos de vida são práticas rotinizadas", portanto esse hábito em comum faz com que possamos perceber compatibilidades entre os estilos de vida dos entrevistados.

Para conseguir entender de maneira mais profunda a frequência de uso, também foi perguntado sobre as situações em que a bicicleta era normalmente usada, assim como as situações nas quais o seu uso era evitado. Os dados obtidos estão expressos na tabela 5 a seguir.

Tabela 5: Situações de Uso

\begin{tabular}{|l|l|l|}
\hline Entrevistado & Situações que usa & Situações em que evita o uso \\
\hline
\end{tabular}




\begin{tabular}{|c|c|c|}
\hline Beatriz Fuchshuber & $\begin{array}{c}\text { Trabalho; Necessidades do dia } \\
\text { a dia; Lazer }\end{array}$ & $\begin{array}{l}\text { Chuva; Longas distâncias; } \\
\text { Trajetos que não possuem } \\
\text { ciclovia }\end{array}$ \\
\hline Gustavo Schaimberg & Faculdade; Lazer & $\begin{array}{c}\text { Chuva; Noite/Madrugada; } \\
\text { Longas distâncias }\end{array}$ \\
\hline João Pedro Tude & $\begin{array}{c}\text { Academia; Pequenas compras } \\
\text { e outras necessidades do dia } \\
\text { a dia }\end{array}$ & $\begin{array}{c}\text { Quando há um grande volume } \\
\text { de objetos para transportar; } \\
\text { Longas distâncias }\end{array}$ \\
\hline $\begin{array}{l}\text { Maria Eduarda } \\
\text { Parada }\end{array}$ & $\begin{array}{c}\text { Trabalho; Mercado; Outras } \\
\text { necessidades do dia a dia; } \\
\text { Lazer }\end{array}$ & Chuva \\
\hline Victor Paiva & Faculdade; Academia; Lazer & Chuva; Longas distâncias \\
\hline
\end{tabular}

Fonte: Próprio Autor (2021)

Beatriz faz uso da sua bicicleta praticamente todos os dias, já que durante a semana sempre a utiliza para ir ao trabalho, e nos finais de semana também é o seu principal meio de transporte para as atividades de lazer. Como lazer, citou ida ao shopping, à praia e à casa de amigos.

O uso de Maria Eduarda também é quase que diário. Constantemente ela tem que se locomover da zona sul até o centro da cidade para fins de trabalho, e costuma fazer isso com a sua bicicleta. Além disso, também tem o hábito de resolver suas necessidades do dia a dia e realizar idas ao mercado com a bicicleta, inclusive mencionou que na semana anterior a entrevista havia se locomovido de Copacabana até a Tijuca para realizar uma compra. Ela enfatizou que, tudo que estiver ao alcance de ser feito com a bicicleta elétrica, faz.

Gustavo utilizava a bicicleta diariamente antes da pandemia do Covid-19, quando a sua faculdade era presencial. Com a pandemia, seu uso diminuiu bastante, e apesar de estar realizando um trabalho de maneira presencial, não utiliza a bicicleta por conta de a distância ser maior. Atualmente o uso ficou restrito para quando há necessidade de uma pequena locomoção e para lazer, como idas ao clube e à praia.

Victor, que possui sua bicicleta há 8 anos, disse que seu uso é quase que diário desde o começo. Assim que comprou a bicicleta, utilizava para ir à escola todos os dias, e depois que iniciou a sua faculdade fez o mesmo, até o momento da interrupção do estudo presencial por conta da pandemia. Apesar dessa quebra no uso constantemente diário, hoje em dia ele ainda usa a bicicleta para ir até a academia e para realizar outras atividades de lazer, como ir à praia por exemplo.

João Pedro, assim como Victor, também relatou usar a bicicleta para ir à academia, e assim como Maria Eduarda, também realiza pequenas compras 
com ela e resolve questões do dia a dia. Como sua compra é recente, ainda não teve experiência com uso diário para ida à faculdade ou trabalho presenciais.

Abordando agora as situações em que o uso desse tipo de transporte é evitado pelos seus usuários, vemos que a chuva e as longas distâncias são questões predominantes, e ambas foram abordadas em 4 das 5 entrevistas como um fator impeditivo.

Além desses 2 fatores, Beatriz informou que a presença da ciclovia na maior parte do trajeto é importante, e viabiliza distâncias um pouco maiores que o uso no próprio bairro. Victor relatou fazer uso de uma motocicleta quando há a necessidade de percorrer distâncias maiores e que não dispõem de ciclovia. Para João, o uso da bike também é evitado quando sabe que irá ter a necessidade de transportar um maior volume de objetos. Gustavo mencionou uma questão diferente dos demais, que se trata do perigo de assalto, e que por esse motivo evita usar a bicicleta em períodos noturnos.

\subsubsection{O Percurso}

Quanto às características do percurso normalmente realizado, também foram coletadas algumas informações, como mostra a tabela 6 :

Tabela 6: Características do Percurso

\begin{tabular}{|l|c|c|}
\hline \multicolumn{1}{|c|}{ Entrevistado } & $\begin{array}{c}\text { Em sua maioria, o trajeto } \\
\text { costuma possuir ciclovia? }\end{array}$ & $\begin{array}{l}\text { Até que distância costuma } \\
\text { percorrer? }\end{array}$ \\
\hline Beatriz Fuchshuber & Sim & Somente pela zona sul \\
\hline Gustavo Schaimberg & Sim & Somente pela zona sul \\
\hline João Pedro Tude & Não & Recreio/Barra \\
\hline Maria Eduarda Parada & Sim & $\begin{array}{c}\text { Zona sul, centro, e as vezes } \\
\text { zona norte }\end{array}$ \\
\hline Victor Paiva & Sim & Somente pela zona sul \\
\hline
\end{tabular}

Fonte: Próprio Autor (2021)

Conseguimos enxergar que os 4 entrevistados que são residentes da zona sul contam com ciclovia na maior parte do seu trajeto, o que contribui para o uso da bike na região. João Pedro, que mora na zona oeste, alegou não ter ciclovia disponível na maioria do seu percurso, e por esse motivo acabou tendo que optar por uma bicicleta mais potente, a fim de diminuir seus riscos.

Maria Eduarda disse apenas não contar com ciclovia quando realiza trajetos um pouco atípicos, como uma ida a zona norte por exemplo, mas que mesmo assim não deixa de fazer o uso da sua bicicleta. 
Vemos também que o uso mais comum da bicicleta é para trajetos mais curtos. Três dos quatro moradores da zona sul afirmaram não sair da região com a bicicleta, percorrendo distâncias que normalmente não são maiores que 10 quilômetros. João Pedro, morador do Recreio, disse que costuma andar mais dentro do próprio bairro, e, no máximo, ir até a Barra da Tijuca. Maria Eduarda foi quem apresentou um uso mais flexível, não se importando muito com distâncias maiores e a presença de ciclovias, desde que a bateria da sua bicicleta seja capaz de suportar.

\subsubsection{Satisfação dos Usuários}

Todos os 5 entrevistados fizeram elogios quanto à praticidade, facilidade $\mathrm{e}$ agilidade que a bicicleta elétrica proporciona para as suas rotinas, sem nem que fosse necessário perguntar, o que já demonstra uma grande satisfação.

Como uma maneira de buscar analisar ainda mais a fundo esse nível de satisfação, foram feitas perguntas sobre situações difíceis e inconvenientes que tiveram que lidar por ter optado pelo uso desse tipo de transporte. Foram relatadas as seguintes ocasiões:

- Fim da bateria e necessidade de pedalar uma bicicleta pesada;

- Defeito na parte elétrica;

- Chuva repentina durante o trajeto;

- Pneu furado;

- Acidente (colisão com outra bicicleta, sem ferimentos graves).

Apesar das diferentes situações de inconveniência abordadas, os entrevistados afirmaram ter sido possível contorná-las com sucesso, e nenhum deles alegou ter se arrependido da compra. Assim como um carro ou uma moto, a bicicleta elétrica também está sujeita a condições adversas e possíveis dificuldades, e é necessário saber lidar com elas. 


\section{Conclusões}

O trabalho apresentado teve como objetivo investigar o comportamento dos consumidores de bicicletas elétricas. O estudo buscou saber, principalmente, quais são os principais fatores que influenciam na compra de uma bicicleta elétrica, assim como avaliar o perfil do público, suas condições de uso e um feedback relacionado a satisfação com a compra.

Com essa finalidade, foi feita uma pesquisa de campo, que contou com a realização de entrevistas com 5 diferentes usuários de bicicletas elétricas. As entrevistas foram feitas baseadas em um roteiro previamente estruturado, composto por 11 perguntas, que se encontra no final deste trabalho.

Através das respostas obtidas, percebemos que o uso da bicicleta elétrica é diferente do uso da convencional, sendo mais adequado para a finalidade de meio de transporte, já que além de promover maior agilidade, evita o cansaço e a transpiração.

Observou-se também que o uso da bicicleta por parte dos entrevistados é bastante frequente, e sua finalidade é variada: estudo, trabalho, academia, lazer, mercado e outras necessidades do dia a dia.

Analisando a distância média percorrida por uso, notamos que ela tende a não ser muito grande na maioria dos casos, raramente passando de 10 quilômetros de casa. Apenas 1 dos 5 entrevistados relatou fazer o uso para viagens cima dessa quilometragem com frequência, e não por acaso, os 4 que não fazem apontaram longas distâncias como uma situação em que o uso é evitado. Considerando isso, este parece ser um dos maiores fatores limitadores da expansão e popularização do uso das bicicletas elétricas, já que muitas pessoas precisam se locomover por distâncias maiores que essa diariamente.

A falta de ciclovias é, sem dúvidas, outro ponto que prejudica essa expansão. $\mathrm{O}$ uso da bicicleta em pistas de carros, principalmente considerando grandes distâncias, se torna perigoso e inadequado para o usuário, fazendo com que ele opte por se transportar de outra maneira.

Percebemos também que, apesar da grande importância para a diminuição da emissão de gases na atmosfera e a consequente preservação do meio ambiente, muitas vezes o consumidor não realiza a compra com esse intuito. De 
acordo com as entrevistas realizadas, vimos que a aquisição de uma bicicleta elétrica é motivada, na maioria das vezes, por questões de comodidade, praticidade e economia. Entretanto, esse benefício não deixa de ser percebido e valorizado pelos seus usuários.

\subsection{Sugestões e Recomendações para Novos Estudos}

Para novos estudos a respeito do tema, sugere-se principalmente uma maior abrangência na seleção dos entrevistados. Levando em consideração que o atual estudo contou com apenas 5 participantes, e todos possuíam idades parecidas, é possível que a pluralidade de respostas tenha sido limitada por conta desse fator.

Não são apenas jovens de 19 a 24 anos que utilizam bicicletas elétricas, portanto recomenda-se a realização de uma investigação mais inclusiva, que conte com a participação das mais variadas idades e perfis, além de dispor de uma maior amostra. Dessa forma, o resultado será mais confiável e enriquecedor.

Outra maneira de aprofundar ainda mais o tema, seria a realização de uma pesquisa que investigasse também as pessoas que não utilizam a bicicleta elétrica, buscando compreender os motivos. Para isso, deveriam ser entrevistadas pessoas que possuem uma rotina na qual o uso de uma bicicleta elétrica seria adequado, ou seja, que conseguem fazer grande parte de suas tarefas nas proximidades de casa. 


\section{Referências Bibliográficas}

ASSOCIAÇÃO BRASILEIRA DO VEÍCULO ELÉTRICO. 2020: O melhor ano da eletromobilidade no Brasil. Disponível em: <http://www.abve.org.br/2020-omelhor-ano-da-eletromobilidade-no-brasil/>. Acesso em 22/09/2021

CASTRO, B. H. R.; FERREIRA, T. T. Veículos elétricos: aspectos básicos, perspectivas e oportunidades. BNDES, p. 267 - 310, 2010.

ENGEL, J .; BLACKWELL, R. ; MINIARD, P. Comportamento do Consumidor. 8 $\mathbf{a}$ ed. Rio de Janeiro: LTC, 2000.

EUROFORUM (2007). Draft paper: State of the Art of Research and Development in the Field of Urban Mobility. The European Research Forum for Urban Mobility (EUROFORUM).

European Enviroment Agency - EEA (1995), Europe's Enviroments: The Dobrís Assessement. Edited by Stanners David \& Bourdeau Philippe. Copenhagen, 1995.

GIDDENS, Anthony. Modernidade e identidade. Rio de Janeiro: Jorge Zahar Ed. 2002.

GUTH, Daniel \& ANDRADE, Victor. Coletânea mercado de bicicletas elétricas no Brasil. Revista Bicicletas Elétricas. Aliança Bike e Labmob, edição n1 2020, disponível em: <https://aliancabike.org.br/wpcontent/uploads/docs/2020/09/Revista-Bicicletas-Eletricas.pdf>. Acesso em: 22/06/2021.

Itaú e startup lançam serviço de aluguel de bicicletas elétricas no RJ. UOL, São Paulo, 25 de setembro de 2020. Disponível em: <https://www.uol.com.br/carros/noticias/redacao/2020/09/25/itau-e-startuplancam-servico-de-aluguel-de-bicicletas-eletricas-no-ri.htm>. Acesso em 21/06/2021.

KLEIMAN, M. Transportes e mobilidade e seu contexto na América Latina. Estudos e Debates no 61. Rio de Janeiro: Ippur, UFRJ, 2011

Kotler, P., \& Keller, K. Administração de marketing. São Paulo: Pearson, 2012.

LANGER, Alexandre. 0 marketing verde. Disponível em:

<http://www.scribd.com/doc/2901707/O-MARKETING-VERDE>. Acesso em: 21 de setembro de 2021.

Mercado de bicicletas elétricas tem crescimento de $34 \%$ no último triênio, aponta caderno técnico lançado pela Aliança Bike. Aliança Bike, 14 de setembro de 2020. Disponível em: <https://aliancabike.org.br/crescimentobicicletas-eletricas/>. Acesso em 21/06/2021. 
NASCIMENTO, Luis Felipe. Gestão Ambiental e Sustentabilidade. Florianópolis: UFSC; CAPES: UAB, 2012.

Peter, J. P., \& Olson, J. C. Consumer Behaviour and Marketing Strategy (7th ed). New York: McGraw-Hill//rwin, 2005.

PINHEIRO, Roberto Meireles; CASTRO, Guilherme Caldas de; SILVA, Helder Haddad;

et al. Consumidor e pesquisa de mercado. Rio de Janeiro: FGV, 2004.

PLUME (2003) - Synthesis Report on Urban Sustainability and its Appraisal, PLUME- Planning for Urban Mobility in Europe.

ROCHA, A. CHRISTENSEN, C., Marketing, Teoria e prática no Brasil. 2. Ed. São Paulo: Atlas, 1999.

SABBAGH, Roberta Buendia. Gestão Ambiental. São Paulo: SMA, 2011.

SALGADO, Diego. Em alta, mercado de bikes elétricas prevê mais crescimento até fim de 2020. UOL, 01 de setembro de 2020. Disponível em:<https://www.uol.com.br/carros/colunas/pedala/2020/09/01/em-alta-mercadode-bikes-eletricas-preve-mais-crescimento-ate-fim-de-2020.htm>. Acesso em: 21/06/2021.

Santamarta, J., (2009) "El futuro del automóvil es eléctrico." Técnica Industrial vol. 281, p. 26.

SOLOMON, Michael R. O comportamento do consumidor: comprando, possuindo e sendo. 9.ed. Porto Alegre: Bookman, 2011. 680 p.

SOLOMON, Michael R. O comportamento do consumidor: comprando, possuindo e sendo, 11 âa edição - Porto Alegre: Bookman, 2015. 608 p.

VELLOSO, J. P. dos R. (2010) - Estratégia de Implantação do Carro Elétrico no Brasil (Vol. XXII Fórum Nacional). Rio de Janeiro, RJ, Brasil.

VENDITTI, Mário Sérgio. Por que carro eletrificado ainda é caro no Brasil. Estadão, 02 de fevereiro de 2021. Disponível em: $<$ https://mobilidade.estadao.com.br/mobilidade-para-que/por-que-carroeletrificado-ainda-e-caro-no-brasil/>. Acesso em 25/06/2021.

VERGARA, S. C. Projetos e Relatórios de Pesquisa em Administração. São Paulo: Editora Atlas, 1998. 
7 Apêndice 1 - Roteiro para Entrevista

1 - Pode me contar um pouco sobre a história de como comprou sua bicicleta elétrica e o que motivou essa compra?

2 - Por que você comprou especificamente essa bicicleta que você tem?

3 - Houve outra razão que também influenciou a sua decisão de compra, mesmo que não tenha sido tão relevante?

4 - Que situações você usa e que situações você deixa de usar a bike elétrica?

5 - Você já passou por alguma dificuldade que fez com que se arrependesse de ter optado pela bicicleta elétrica?

6 - Qual a distância média que você costuma percorrer com a bicicleta?

7 - Com que frequência você a utiliza?

8 - No seu trajeto costuma ter ciclovia?

9 - Há quanto tempo você tem a bicicleta?

10 - Você já andava de bicicleta antes de comprar a elétrica?

11 - A questão da sustentabilidade influenciou a sua escolha pela bicicleta elétrica? 